\title{
Cytotoxic T-lymphocyte antigen-4 +49A/G polymorphisms in Sudanese adults with type 1 diabetes and latent autoimmune diabetes
}

\author{
Shimos A. Alshareef ${ }^{1,2}$, Saeed M. Omar ${ }^{3}$, Hamdan Z. Hamdan ${ }^{4}$ and Ishag Adam*
}

\begin{abstract}
Objectives: This study was conducted to assess the association of T-lymphocyte-associated protein 4 (CTLA-4 $+49 \mathrm{~A} / \mathrm{G}$ ) variant with Latent autoimmune diabetes in adults (LADA) in Eastern Sudan. The study included 24 LADA, 240 patients with type 1 diabetes mellitus (T1DM), and 240 healthy controls. Genotyping for CTLA-4 +49A/G was done by polymerase chain reaction restriction fragment length polymorphism (PCR-RFLP).

Results: Genotypes distribution of CTLA-4 in controls was in accordance with the HWE $(P>0.05)$. The frequency of mutation (both homozygous and heterozygous) of CTLA-4 +49A/G (AG + GG) was significantly higher in LADA compared with T1DM and the controls [19 (79.1\%) vs. 100 (41.7\%) vs. 78 (32.5\%), P<0.001]. It was significantly higher when LADA was compared with T1DM [19 (79.1\%) vs. 100 (41.7\%), $\mathrm{P}=0.018, \mathrm{OR}=3.21,95 \% \mathrm{Cl} 1.16-8.89$ ] and when LADA was compared with the controls [19 (79.1\%) vs. 78 (32.5\%), $\mathrm{P}=0.001, \mathrm{OR}=4.49,95 \% \mathrm{Cl} 1.62-12.42]$. The rate of heterozygous mutation of the CTLA-4 +49A/G (AG) was significantly higher in LADA compared with T1DM and the controls [16 (66.7\%) vs. 85 (35.4\%) vs. 70 (29.2\%), P<0.001]. It was significantly higher when LADA was compared with T1DM [16 (66.7\%) vs. 85 (35.4\%), $\mathrm{P}=0.002, \mathrm{OR}=3.64,95 \% \mathrm{Cl} 1.49-8.87]$ and when LADA was compared with the controls [16 (66.6\%) vs. 85 (35.4\%), $\mathrm{P}=0.001, \mathrm{OR}=4.85,95 \% \mathrm{Cl} 1.98-11.86]$.
\end{abstract}

Keywords: Autoantibodies, Cytotoxic T-lymphocyte antigen-4, Latent autoimmune diabetes in adults, Polymorphism, Type 1 diabetes mellitus, Sudan

\section{Introduction}

Latent autoimmune diabetes in adults (LADA) is the term coined to type 1 diabetes mellitus (T1DM) which has similar clinical features of type 2 diabetes (T2DM) mellitus, however it has slower immunizing damage of $\beta$-cells than found in T1DM [1]. LADA accounts for $4-12 \%$ of adults with T2DM $[2,3]$.

The detection of circulatory islet cell autoantibodies [glutamic acid decarboxylase antibodies (GADAs) and islet antigen-2 (IA-2As)] which are the main features for T1DM and LADA, could explain the beta cell damage which is caused by cytotoxic $\mathrm{T}$ lymphocytes

\footnotetext{
*Correspondence: ishagadam@hotmail.com

${ }^{5}$ Faculty of Medicine, University of Khartoum, P.O. Box 102 Khartoum, Sudan
}

Full list of author information is available at the end of the article
[4]. Although, the genetic basis of LADA is not yet fully understood, previous studies have reported that LADA patients have shared some genetic features with both T1DM and T2DM [5, 6]. Cytotoxic T-lymphocyte antigen-4 (CTLA-4) can act a co-stimulatory molecule which is expressed on activated $\mathrm{T}$ lymphocytes and possess a key role in autoimmunity via down regulating T-cell function [7]. The CTLA-4 gene is located on chromosome 2 (2q33) and it has been shown that CTLA-4 is associated with various autoimmune diseases such as T1DM, Graves' disease and asthma [7-10].

There are few published researches on association between LADA and CTLA-4 [5, 11-14] and there is no existing publication on association between LADA and CTLA-4 in Sub-Saharan Africa including Sudan. Diabetes is a big health problem in Sudan [15]. The current 
study was conducted to investigate the role of CTLA4 on the susceptibility of LADA in eastern Sudan.

\section{Main text Methods}

A case-control study was conducted in Gadarif Teaching Hospital clinic in the eastern Sudan during the period of February through August 2017. The cases (were part of the patient who had the initial clinical diagnosis of T2DM) were 24 patients with LADA which was diagnosed by the criteria of their age at onset of diabetes was $>30$ years, did not require insulin for at least 6 months after diagnosis and the presence of circulating GAD65 antibodies [4]. Two groups of controls were selected. The first group of controls were 240 patients who presented with T1DM to the hospital during the study period and who developed diabetic ketosis or ketoacidosis at onset and required insulin treatment at the time of diabetes diagnosis. The other control group were 240 healthy individuals (age- and sex-matched) with no family history of diabetes or autoimmune diseases. A total of $240(44.5 \pm 3.6$ years; M/F:118/122) clinically characterized T2DM patients, who had been on oral treatment for at least 3 months, were screened for LADA by detecting the presence of GAD65 and IA-2 autoantibodies in the serum using ELISA as the manufacturer described (Anti-GAD/IA2 pool ELISA Test, Euroimmune, Germany). From these T2DM group, 24 patients were identified and labelled as LADA cases.

The LADA positive samples were selected for genotyping analysis for CTLA-4 $+49 A / G$ gene polymorphism, were compared to a similar number of T1DM patients and normal control subjects. PCR-restriction fragment length polymorphism (PCR-RFLP) in $+49 \mathrm{~A} / \mathrm{G}$ position was used for genotyping. Genomic DNA from peripheral blood leukocytes was extracted as described previously [16]. PCR was performed using Forward primer (5'-GCT CTACTTCCTGAAGACCT-3 $3^{\prime}$ ) and Reverse primer $\left(5^{\prime}\right.$ AGTCTCACTCACCTTTGCAG-3') according to the previous method [17]. PCR products were subjected to restriction digestion with BbV1 restriction enzyme (Fermentas Life Sciences, Germany) using the supplier's protocol. The restriction products were proceeded in $2 \%$ agarose gel electrophoresis in order to visualize the CTLA-4 sequence (162-bp). If a $\mathrm{G}$ was found at position $49, B b v I$ cut the sequence, resulting in 88/74-bp fragments, while the sequence was intact if an $\mathrm{A}$ was located in the same position, Fig. 1.

\section{Statistics}

SPSS was used for data analyses. The clinical data were compared between LADA, T1DM and the controls by t-test and Chi square test for continuous and categorized

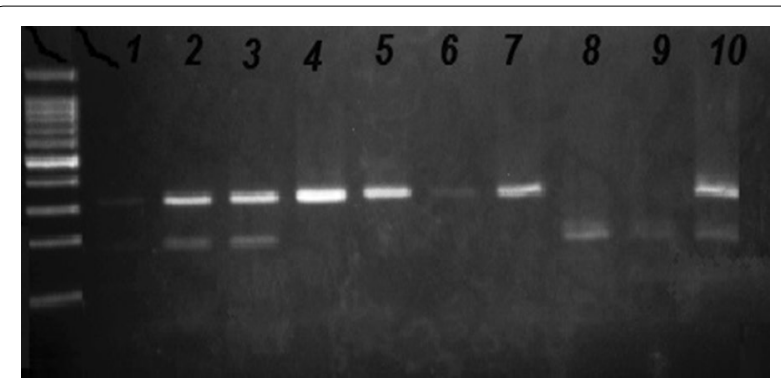

Fig. 1 PCR-RFLP analysis for CTLA-4 +49A/G polymorphism. Two fragments of $74 / 88$ bp indicate homozygous $(\mathrm{G} / \mathrm{G})$, three fragments of 74, 88 and 162 bp indicate heterozygous genotype (A/G) and undigested fragment of $162 \mathrm{bp}$ indicate homozygous A/A genotype. Lane $L$ show the 50 bp ladder; Lane1 blank control

data, respectively. Hardy-Weinberg equilibrium (HWE) was performed to compare the observed frequencies of the different genotype distribution with their expected frequency in the controls groups by using Pearson's Chi square $\left(X^{2}\right)$ statistical test [18]. The genotypes and alleles difference between the LADA, T1DM and the controls were compared by Pearson's Chi square $\left(x^{2}\right)$ statistical test. A two-sided $P$-value $<0.05$ was considered statistically significant.

Genotype risk was calculated by multiplying the genotype of the SNP for each individual by the effect size ( $\beta$-coefficient) and summing the individual score as described previously [19]. Binary regression analysis was used to build risk model by using phenotype LADA as a dependent factor and the covariates e.g. age, sex and body mass index (BMI) as independent factor. Firstly, covariates age, sex and BMI were calculated in model 1 . Then weighted genetic risk score was entered as a single covariate in model 2. At last all covariates including weighted genetic risk score were included in model 3 . Both, $R^{2}$ and $X^{2}$ were calculated for each model.

\section{Results}

The three groups were matched in their age and sex. LADA antibodies were observed in 24 patients (10.0\%). Healthy controls showed no autoantibodies.

Genotypes distribution of CTLA-4 in controls was in accordance with the HWE $(P>0.05)$.

The frequency of mutation (both homozygous and heterozygous) of CTLA-4 +49A/G (AG + GG) was significantly higher in LADA compared with T1DM and the controls $[19(79.1 \%)$ vs. $100(41.7 \%)$ vs. 78 (32.5\%), $\mathrm{P}<0.001]$. It was significantly higher when LADA was compared with T1DM [19 (79.1\%) vs. 100 (41.7\%), $\mathrm{P}=0.018, \mathrm{OR}=3.21,95 \% \mathrm{CI} 1.16-8.89]$ and when LADA was compared with the controls [19 (79.1\%) vs. 78 (32.5), $\mathrm{P}=0.001, \mathrm{OR}=4.49,95 \% \mathrm{CI} 1.62-12.42]$. There was no 
significant difference in the CTLA-4 +49A/G mutation between the T1DM and the controls, Table 1.

The rate of heterozygous mutation of the CTLA-4 $+49 \mathrm{~A} / \mathrm{G}(\mathrm{AG})$ was significantly higher in LDA compared with T1DM and the controls [19 (79.1\%) vs. $100(41.7 \%)$ vs. 78 (32.5\%), $\mathrm{P}<0.001$ ]. It was significantly higher when LADA was compared with T1DM [19 (79.1\%) vs. 100 (41.7\%), $\mathrm{P}=0.018, \mathrm{OR}=3.21,95 \% \mathrm{CI} 1.16-8.89]$ and when LADA was compared with the controls [16 (66.6\%) vs. 70 (14.6\%), $P=0.001$, $\mathrm{OR}=4.49,95 \% \mathrm{CI} 1.62-12.42$ ], Table 1 . The homozygous rate of the CTLA- $4+49 \mathrm{~A} / \mathrm{G}$ (GG) mutation was not different between the LADA, T1DM and the controls, Table 1.

Regression analysis showed that, weighted genetic risk score was a significant risk factor for developing LADA in model 3, $\mathrm{OR}=2.82(1.71-4.65) ; P=<0.001$. Likewise, BMI remained as a risk factor in model 3 when it was combined with genetic risk score, $\mathrm{OR}=1.03$ (1.01-1.06); $P=0.003$, Table 2 .

\section{Discussion}

The current study showed a higher frequency of heterozygous mutation of CTLA-4 $+49 A / G$ in the LADA compared with T1DM and the controls. However, the rate of the homozygous mutation of CTLA-4 +49A/G was not different between the LADA, T1DM and the controls. It seems to be this is the first report on
Table 2 Regression model for evaluating genetic risk of LADA patients

\begin{tabular}{llr}
\hline Variables & OR $\mathbf{( 9 5 \% ~ C l )}$ & $P$-value \\
\hline Model 1 & $0.99(0.94-1.05)$ & 0.901 \\
Age (years) & $1.42(0.62-3.26)$ & 0.404 \\
Sex & $1.03(1.00-1.05)$ & 0.013 \\
BMl, kg/m² & & 0.095 \\
$X^{2}=6.3761$ & & \\
$R^{2}=0.04$ & $2.53(1.56-4.11)$ & \\
Model 2 & & $<0.001$ \\
WGRS & & \\
$X^{2}=13.84$ & & $<0.001$ \\
$R^{2}=0.085$ & $2.82(1.71-4.65)$ & 0.863 \\
Model 3 & $0.99(0.94-1.05)$ & 0.480 \\
WGRS & $1.35(0.57-3.19)$ & 0.003 \\
Age (years) & $1.03(1.01-1.06)$ & $<0.001$ \\
Sex & & \\
BMl, kg/m² & & \\
$X^{2}=22.6$ & & \\
$R^{2}=0.138$ & &
\end{tabular}

$B M I$ body mass index, $C l$ confidence intervals, $O R$ odds ratio, wGRS weighted genetic risk score

association of CTLA-4 $+49 A / G$ genotypes and diabetes mellitus in Sub-Saharan Africa. Previous studies reported a significant association between the CTLA-4 $+49 A / G$

Table 1 The frequency (\%) of CTLA-4 +49 A/G polymorphism

\begin{tabular}{|c|c|c|c|c|c|c|}
\hline $\begin{array}{l}\text { Genotype } \\
\text { frequencies }\end{array}$ & LADA (24) & T1DM control (240) & Healthy control (240) & $P$ & OR & $95 \% \mathrm{Cl}$ \\
\hline \multirow[t]{4}{*}{$\mathrm{AA}$} & $5(20.8)$ & $140(58.3)$ & $162(67.5)$ & All $<0.001$ & & \\
\hline & & & & LADA vs. $T 1 D M=0.001$ & 0.18 & $0.06-0.52$ \\
\hline & & & & LADA vs. controls $=0.001$ & 0.12 & $0.04-0.35$ \\
\hline & & & & T1DM vs. controls $=0.037$ & 0.67 & $0.46-0.97$ \\
\hline \multirow[t]{4}{*}{$A G$} & $16(66.7)$ & $85(35.4)$ & $70(29.2)$ & All $<0.001$ & & \\
\hline & & & & LADA vs. T1DM $=0.002$ & 3.64 & $1.49-8.87$ \\
\hline & & & & LADA vs. controls $=0.001$ & 4.85 & $1.98-11.86$ \\
\hline & & & & T1DM vs. controls $=0.143$ & 1.33 & $0.90-1.95$ \\
\hline \multirow[t]{4}{*}{ GG } & $3(12.5)$ & $15(6.3)$ & $8(3.3)$ & All 0.087 & & \\
\hline & & & & LADA vs. $T 1 D M=0.598$ & 0.74 & $0.20-2.50$ \\
\hline & & & & LADA vs. controls $=0.598$ & 0.74 & $0.20-2.50$ \\
\hline & & & & T1DM vs. controls $=0.990$ & 1.00 & $0.61-1.61$ \\
\hline \multirow[t]{4}{*}{$\mathrm{AG}+\mathrm{GG}$} & $19(79.1)$ & $100(41.7)$ & $78(32.5)$ & All $<0.001$ & & \\
\hline & & & & LADA vs. $T 1 D M=0.018$ & 3.21 & $1.16-8.89$ \\
\hline & & & & LADA vs. controls $=0.001$ & 4.49 & $1.62-12.42$ \\
\hline & & & & T1DM vs. controls $=0.067$ & 1.73 & $0.97-2.00$ \\
\hline Allele A & $26(54.2)$ & $365(76.0)$ & $394(82.1)$ & All $<0.001$ & & \\
\hline \multirow[t]{3}{*}{ Allele $\mathrm{G}$} & $22(45.8)$ & $115(24.0)$ & $86(18.0)$ & LADA vs. T1DM $<0.001$ & 0.37 & $0.20-0.68$ \\
\hline & & & & LADA vs. controls $<0.001$ & 0.25 & $0.13-0.47$ \\
\hline & & & & T1DM vs. controls $=0.021$ & 0.69 & $0.50-0.94$ \\
\hline
\end{tabular}


polymorphism and the susceptibility to LADA and T1DM in different settings e.g. China [11, 13], Estonia [20, 21], Spain and Italy [22], Poland [23] and Argentina [14]. Furthermore, recent systematic review demonstrated that CTLA-4 $+49 A / G$ polymorphism is associated with LADA [9].

On the other hand Delitala et al.,-who have investigated CTLA-4 G6230A variant in Sardinian population (Italy)-reported no significant difference in the distribution of G6230A genotypes and alleles in LADA patients, early and late-onset T1D patients, and healthy controls [12]. Likewise Shih et al., observed no significant association between CTLA-4 +49 genotypes with T2DM [24]. It noteworthy that, $C T L A-4+49 A / G$ is a missense variant that is located in exon 1 at position 49. This missense variant resulted in changing the hydrophilic amino acid threonine to a non-polar amino acid alanine [10]. The replaced amino acid is located in the leading sequence of the CTLA-4, which may affect the folding or migration of the CTLA-4 protein towards the T-cell receptor. From another prospective, Ueda et al., confirmed that, carrier of homozygous risky genotype G/G express about half of the amount that expressed by the subject who have a protective homozygous genotype A/A [7]. Moreover, Anjos and his colleagues reported that, CTLA- 4 peptide translated from G/G genotype individuals is subjected to malhandling of the peptide by endoplasmic reticulum. This is result in glycosylation of the CTLA-4 peptide which decrease the subsequence cellular expression. On the other hand individuals who have the protective genotype A/A have a well handled and processed CTLA-4 peptide and end up with successful cellular expression [25]. Perhaps, this provide the rational of malfunctioning and loss of the T-cell inhibition observed in activated cytotoxic $\mathrm{T}$-cell functions in patients with autoimmune diseases [26].

It is worth to be mentioned that our results should be cautiously compared with the results of the later studies because of the ethnicity difference between the various settings.

\section{Conclusion}

The CTLA-4 $+49 A / G$ polymorphism is associated with development of LADA in this setting.

\section{Limitations of the study}

In number (hence the sample size) of the LADA was small in this study and this might have effect of the power. Other markers and genotypes were not investigated. Gadarif is located on Ethiopian border and Sudanese population might not be of the same ethnicity.

\section{Abbreviations}

LADA: latent autoimmune diabetes in adults; CTLA4: cytotoxic T-lymphocyte associated protein 4; T1DM: type 1 diabetes mellitus; T2DM: type 2 diabetes mellitus.

\section{Acknowledgements}

We would like to thank the patients for participating in this study.

\section{Authors' contributions}

SAA and IA conceived and designed the study. SMO and $\mathrm{HZH}$ recruited the participants. SAA and HZH performed the laboratory work. SMO and IA analysed the data and wrote the manuscript. All contributed authors of this original manuscript authorized the final version of the manuscript. All authors read and approved the final manuscript.

\section{Funding}

None received.

\section{Availability of data and materials}

The datasets used and/or analysed during the current study are available from the corresponding author on reasonable request.

\section{Ethics approval and consent to participate}

The study received ethical approval from the Research Board at the Faculty of Medicine, University of Gadarif, Sudan. The reference number is $2016 / 39$. Written informed consent was obtained from all the enrolled patients.

\section{Consent for publication}

Not applicable.

\section{Competing interests}

The corresponding author (Ishag Adam) is an Associate Editor in BMC Research Notes Journal. Other authors declare that they have no competing interests.

\section{Author details}

${ }^{1}$ Al-Ghad International College for Applied Medical Sciences, Medina, Kingdom of Saudi Arabia. ${ }^{2}$ Central Laboratory, Khartoum, Sudan. ${ }^{3}$ Faculty of Medicine, Gadarif University, Gadarif, Sudan. ${ }^{4}$ Faculty of Medicine, Al-Neelain University, Khartoum, Sudan. ${ }^{5}$ Faculty of Medicine, University of Khartoum, P.O. Box 102 Khartoum, Sudan.

Received: 5 June 2019 Accepted: 16 November 2019

Published online: 26 November 2019

References

1. Naik RG, Brooks-Worrell BM, Palmer JP. Latent autoimmune diabetes in adults. J Clin Endocrinol Metab. 2009;94:4635-44.

2. Buzzetti R, Di Pietro S, Giaccari A, Petrone A, Locatelli M, Suraci C, et al. High titer of autoantibodies to GAD identifies a specific phenotype of adult-onset autoimmune diabetes. Diabetes Care. 2007;30:932-8.

3. Borg H, Gottsäter A, Landin-Olsson M, Fernlund P, Sundkvist G. High levels of antigen-specific islet antibodies predict future beta-cell failure in patients with onset of diabetes in adult age. J Clin Endocrinol Metab. 2001;86:3032-8.

4. Fourlanos S, Dotta F, Greenbaum CJ, Palmer JP, Rolandsson O, Colman PG, et al. Latent autoimmune diabetes in adults (LADA) should be less latent. Diabetologia. 2005;48:2206-12.

5. Cervin C, Lyssenko V, Bakhtadze E, Lindholm E, Nilsson P, Tuomi T, et al. Genetic similarities between latent autoimmune diabetes in adults, type 1 diabetes, and type 2 diabetes. Diabetes. 2008;57:1433-7.

6. Andersen MK, Lundgren V, Turunen JA, Forsblom C, Isomaa B, Groop P-H, et al. Latent autoimmune diabetes in adults differs genetically from classical type 1 diabetes diagnosed after the age of 35 years. Diabetes Care. 2010;33:2062-4. 
7. Ueda H, Howson JMM, Esposito L, Heward J, Snook H, Chamberlain G, et al. Association of the T-cell regulatory gene CTLA4 with susceptibility to autoimmune disease. Nature. 2003;423:506-11.

8. Wang K, Zhu Q, Lu Y, Lu H, Zhang F, Wang X, et al. CTLA-4 +49 G/A polymorphism confers autoimmune disease risk: an updated meta-analysis. Genet Test Mol Biomarkers. 2017;21:222-7.

9. Dong $\mathrm{F}$, Yang G, Pan H-W, Huang W-H, Jing L-P, Liang W-K, et al. The association of PTPN22 rs2476601 polymorphism and CTLA-4 rs231775 polymorphism with LADA risks: a systematic review and meta-analysis. Acta Diabetol. 2014;51:691-703.

10. Chen Z, Fei M, Fu D, Zhang L, Ma Y, Wang Y, et al. Association between cytotoxic T lymphocyte antigen-4 polymorphism and type 1 diabetes: a meta-analysis. Gene. 2013;516:263-70. https://doi.org/10.1016/j. gene.2012.12.030.

11. Jin P, Xiang B, Huang G, Zhou Z. The association of cytotoxic T-lymphocyte antigen-4 +49A/G and CT60 polymorphisms with type 1 diabetes and latent autoimmune diabetes in Chinese adults. J Endocrinol Invest. 2015;38:149-54.

12. Delitala AP, Fanciulli G, Zoledziewska M, Pitzalis M, Pusceddu P, Frongia P, et al. Allelic variant in CTLA4 is associated with thyroid failure and faster $\beta$-cell exhaustion in latent autoimmune diabetes in adults. J Diabetes. 2015;7:68-73.

13. Jin P, Huang G, Lin J, Yang L, Xiang B, Zhou W, et al. High titre of antiglutamic acid decarboxylase autoantibody is a strong predictor of the development of thyroid autoimmunity in patients with type 1 diabetes and latent autoimmune diabetes in adults. Clin Endocrinol (Oxf). 2011;74:587-92.

14. Caputo M, Cerrone GE, López AP, Villalba A, Krochik GA, Cédola FN, et al. Cytotoxic T lymphocyte antigen 4 heterozygous codon 49 A/G dimorphism is associated to latent autoimmune diabetes in adults (LADA). Autoimmunity. 2005;38:277-81.

15. Omar SM, Musa IR, Osman OE, Adam I. Assessment of glycemic control in type 2 diabetes in the Eastern Sudan. BMC Res Notes. 2018;11:1-5.

16. Miller SA, Dykes DD, Polesky HF. A simple salting out procedure for extracting DNA from human nucleated cells. Nucleic Acids Res. 1988;16:1215

17. Abe $\mathrm{T}$, Takino $\mathrm{H}$, Yamasaki $\mathrm{H}$, Ozaki M, Sera Y, Kondo H, et al. CTLA4 gene polymorphism correlates with the mode of onset and presence of ICA512 Ab in Japanese type 1 diabetes. Diabetes Res Clin Pract. 1999;46:169-75.
18. Michael C. A simple calculator to determine whether observed genotype frequencies are consistent with Hardy-Weinberg equilibrium. www.tufts .edu/ mcourt01/Documents/Courtlab-HW Calc. 2008.

19. Lin X, Song K, Lim N, Yuan X, Johnson T, Abderrahmani A, et al. Risk prediction of prevalent diabetes in a Swiss population using a weighted genetic score-the CoLaus Study. Diabetologia. 2009;52:600-8. https:// doi.org/10.1007/s00125-008-1254-y.

20. Kisand K, Uibo R. LADA and T1D in Estonian population - two different genetic risk profiles. Gene. 2012;497:285-91.

21. Douroudis K, Prans E, Kisand K, Nemvalts V, Uibo R. Cytotoxic T-lymphocyte antigen 4 gene polymorphisms are associated with latent autoimmune diabetes in adults. Clin Chim Acta. 2009:403:226-8.

22. Marron MP, Raffel LJ, Garchon HJ, Jacob CO, Serrano-Rios M, Martinez Larrad MT, et al. Insulin-dependent diabetes mellitus (IDDM) is associated with CTLA4 polymorphisms in multiple ethnic groups. Hum Mol Genet. 1997;6:1275-82. https://doi.org/10.1093/hmg/6.8.1275.

23. Krokowski M, Bodalski J, Bratek A, Machejko P, Caillat-Zucman S. CTLA-4 gene polymorphism is associated with predisposition to IDDM in a population from central Poland. Diabetes Metab. 1998;24:241-3.

24. Shih Y-L, Lu H-F, Hsiao C-W, Ho K-T, Chen P-C, Huang C-N, et al. Distribution of cytotoxic T lymphocyte-associated antigen-4 promoter polymorphisms in Taiwanese patients with type 2 diabetes mellitus. Int J Med Sci. 2018;15:395-402.

25. Anjos S, Nguyen A, Ounissi-Benkalha H, Tessier M-C, Polychronakos C A common autoimmunity predisposing signal peptide variant of the cytotoxic T-lymphocyte antigen 4 results in inefficient glycosylation of the susceptibility allele. J Biol Chem. 2002;277:46478-86. https://doi. org/10.1074/jbc.M206894200.

26. Vaidya B, Pearce SHS, Charlton S, Marshall N, Rowan AD, Griffiths ID, et al. An association between the CTLA4 exon 1 polymorphism and early rheumatoid arthritis with autoimmune endocrinopathies. Rheumatology. 2002;41:180-3. https://doi.org/10.1093/rheumatology/41.2.180.

\section{Publisher's Note}

Springer Nature remains neutral with regard to jurisdictional claims in published maps and institutional affiliations.
Ready to submit your research? Choose BMC and benefit from:

- fast, convenient online submission

- thorough peer review by experienced researchers in your field

- rapid publication on acceptance

- support for research data, including large and complex data types

- gold Open Access which fosters wider collaboration and increased citations

- maximum visibility for your research: over $100 \mathrm{M}$ website views per year

At BMC, research is always in progress.

Learn more biomedcentral.com/submissions 